\title{
Improving food security for Labrador Inuit in Nunatsiavut, Labrador: A matter of health equity
}

\author{
Renee Bowers ( $\square$ rbowe070@uottawa.ca ) \\ uOttawa: University of Ottawa \\ Gail Turner \\ Labrador Inuit Land Claims Beneficiary \\ Ian D. Graham \\ Ottawa Health Research Institute: Ottawa Hospital Research Institute \\ Chris Furgal \\ Trent University \\ Lise Dubois \\ University of Ottawa Faculty of Medicine
}

Research

Keywords: Food security, Inuit, Policy, Equity

Posted Date: November 11th, 2021

DOI: https://doi.org/10.21203/rs.3.rs-1056651/v1

License: (a) (1) This work is licensed under a Creative Commons Attribution 4.0 International License. Read Full License 


\section{Abstract}

Background The current low state of food security amongst Inuit in Canada is influenced by policy choices. Policy actors develop and implement policies, yet few research studies include their perspectives. This study includes policy actors' perspectives on gaps and areas of improvement for policies that pertain to food security for Labrador Inuit in Nunatsiavut. Nunatsiavut is one of the four Inuit land claim areas in northern Canada making up the Inuit homeland, or Inuit Nunangat. It is situated in northern Labrador in the province of Newfoundland and Labrador, Canada. Methods This qualitative study consisted of key informant interviews conducted from July 2020-December 2020 with policy actors that spanned the Nunatsiavut Government (regional Inuit government), Government of Newfoundland and Labrador (provincial government), the Government of Canada (federal government), non-governmental organizations and private industry. Participants were asked about their role, policy gaps and opportunities for improving policies that pertain to food security in Nunatsiavut. It also included initial insights from emergency food security measures implemented during the first wave of COVID-19 in 2020. Results Fifteen key informant interviews were completed, and three participants provided written responses. The results were reported as per the consolidated criteria for reporting qualitative studies (COREQ): 32-item checklist. Seven participants (39\%) stated they developed policy, six participants (33\%) stated they both developed and implemented policy and five participants (28\%) stated they implemented policy. Seven themes were identified from discussions with policy actors. Policy recommendations to improve food security include improving transportation, social policies, and policy coherence in policy implementation. Five separate themes were identified from discussions on implementing emergency food security measures during the first wave of COVID-19 in Nunatsiavut. These included inadequacy of social policies, hidden poverty among people living in Nunatsiavut and future considerations for post- COVID-19 food security policies. Conclusion The results of this study show that improving food security in Nunatsiavut is a matter of health equity. During COVID-19, these inequities were further highlighted, demonstrating the importance of urgent action. Findings from this study can inform actions to improve existing and future policies that pertain to food security for Labrador Inuit in Nunatsiavut.

\section{Background}

Inuit in Canada are among the least food secure in the developed world (1). Food security is a social determinant of Inuit health (2). The World Health Organization states that social determinants of health are "the conditions in which people are born, grow, live, work and age, including the health system. These circumstances are shaped by the distribution of money, power and resources at global, national and local levels" (3). These circumstances are influenced by policy choices (2). Policy choices are influenced by many factors including the evidence, stakeholder advocacy and the economic and political context (4). In the last 15 years, research has increased on the topic of policy measures to improve food insecurity in Canada (5-15). Despite this increase, this research area remains underdeveloped in comparison to community-based interventions. Bastian and Coveney noted in their review of food security interventions that over three times as many articles focused on local level programs, in comparison to the number of articles focused on potential policy changes to improve food security (16).

For Inuit in Canada, policy research on food security needs to consider both the policy subject and how the policy is developed. For Inuit, this creates meaningful policies (1) and is an important part of Inuit self-determination in Canada. Indigenous selfdetermination and engagement are outlined in article three and article 19 of the United Nations Declaration on the Rights of Indigenous Peoples. Article three declares "Indigenous Peoples are guaranteed the right to freely determine their political condition and the right to freely pursue their form of economic, social and cultural development" (17). Article 19 declares "States shall consult and cooperate in good faith with the Indigenous peoples concerned through their own representative institutions in order to obtain their free, prior and informed consent before adopting and implementing legislative or administrative measures that may affect them" (17).

However, the interpretation of self-determination varies with the lens from which it is viewed. From a political science perspective, self-determination links two concepts-autonomy, which aims to restore autonomy to Indigenous Peoples over matters that affect their daily lives, and integration, which is Indigenous Peoples' ability to influence decisions of non-Indigenous governments that may still have the authority to make decisions that impact Indigenous communities. They refer to these two concepts as self-rule and shared rule (18). The United Nations Declaration on the Rights of Indigenous Peoples definition of self-determination and the political science perspective on self-determination agree on the premise that Indigenous Peoples should have ownership over their decisions. However, they differ on the scope of Indigenous Peoples' influence on policies that affect them. Free and informed prior

Page 2/22 
consent as outlined in article 19 of United Nations Declaration on the Rights of Indigenous Peoples is different than ability to influence. This is an important distinction as the lens of self-determination used in policy making processes can influence the degree to which Indigenous Peoples are engaged in the policy development and implementation process and whether defined mechanisms exist to support these processes.

Policy actors are defined as "any individual or group that is directly or indirectly, formally or informally, affiliated with or affected by the policy process at any stage. They can include governments, businesses, non-government organizations, civil society organizations and communities as well as individuals" (19). There is a scant amount of research on policy actors' roles or their perspectives on policies that pertain to food security for the general Canadian population and/or Indigenous Peoples in Canada in particular. Instead, the research tends to focus on the effectiveness of a single policy and its impact on those living with food insecurity (5-15). In 2018, McIntyre et al. (20) completed a survey of policy actors for food insecurity in Canada. Study results identified policy actors' roles and their connections within a national food security policy network. For policy actors such as the Inuit Tapiriit Kanatami, a national Inuit organization in Canada, policy recommendations to improve food security form the basis of their advocacy efforts (21-24). These efforts include a variety of mechanisms such as the Inuit-Crown Partnership Committee, which is a permanent bilateral mechanism between Inuit in Canada, and the Prime Minister of Canada (25).

This study focuses on policy actors from three governments, nongovernmental organizations and private industry who are involved with development and implementation of policies that pertain to food security for Labrador Inuit in Nunatsiavut. Nunatsiavut is one of the four Inuit land claim areas in Canada and is located in northern Labrador, in the Canadian province of Newfoundland and Labrador. The land claim area has its own Inuit self-government. The Nunatsiavut Government was formed in 2005 after the Labrador Inuit Association, Government of Canada, and Government of Newfoundland and Labrador signed the Labrador Inuit Land Claims Agreement (26). Due to the geographic location and the Labrador Inuit Land Claims Agreement, policy actors spanned three governments -the Government of Canada (federal government), the Newfoundland and Labrador Government (provincial government) and the Nunatsiavut Government (regional Inuit government). Policy actors also span nongovernment organizations, national Inuit organizations and private industry that make policy recommendations, advocate for policies and have a role in policy implementation. Moreover, this study took place after emergency food security measures were implemented in Nunatsiavut during the first wave of COVID-19 in 2020 (27). This study provides insights from policy actors on policies that pertain to food security in both usual and emergency circumstances for Labrador Inuit, an Indigenous population in northern Labrador.

\section{Methods}

\section{Study aims}

This qualitative study consisted of key informant interviews conducted with policy actors who work with policies that pertain to food security in Nunatsiavut. This study primarily aims to answer research questions focused on policy actors' roles and perspectives on improving policies that pertain to food security in Nunatsiavut. The questions consisted of: What are the roles of the policy actors? Was the Labrador Inuit context considered in policy development? How could policies be improved to address food security in Nunatsiavut? Are there any gaps in policies for food security in Nunatsiavut? And, who is ultimately responsible for food security in Nunatsiavut? The timing of this study coincided with initial emergency food security responses implemented in Nunatsiavut during the first wave of COVID-19 in Canada (March 2020-July 2020). During this time, specific emergency food security measures were implemented for Labrador Inuit and are described later in this article. Accordingly, a secondary set of research questions focused on the COVID-19 measures that consisted of: Has COVID-19 raised the priority of food security within the respective department/organization? Has COVID-19 highlighted any vulnerabilities in the food system? Were additional actions taken to address food security during COVID-19?

\section{Study design}

The research team consisted of five members, RB is a dietitian and a Ph.D. Candidate with the University of Ottawa who is from Labrador. GT is Inuit and a beneficiary of the Labrador Inuit Land Claim, who retired in 2012 from the position of Director of Health Services for the Nunatsiavut Government, Northern Labrador. CF is a researcher focusing on environmental health risk assessment, management and communication in cooperation with Indigenous populations and communities living in rapidly changing

Page $3 / 22$ 
environments such as coastal and Arctic ecosystems. CF is a professor and Director of the Indigenous Environmental Studies and Sciences Program at Trent University. IDG is a sociologist and health services researcher who studies knowledge translation and research co-production. He is a professor in the school of epidemiology and public health at the University of Ottawa and senior scientist at the Ottawa Hospital Research Institute. LD, a dietitian and Ph.D. in sociology is a full professor with the Faculty of Medicine School of Epidemiology and Public Health, University of Ottawa and her expertise is on nutrition and social inequalities at the population level. The research team developed the interview questions through an iterative process with a Nunatsiavut Government Advisory Group for this research project.

The Nunatsiavut Government Advisory Group spans several departments within the Nunatsiavut Government. The research team identified key topics through an initial discussion and developed specific questions. The Nunatsiavut Government Advisory group provided feedback on these questions, which included revising existing questions and adding additional questions. These questions were then divided into four sections that focused on the policy role, areas of improvement, policy gaps, who people worked with on a specific policy, questions specifically focused on the COVID-19 pandemic and food security in Nunatsiavut. Additionally, through the two ethics review processes, one from the University of Ottawa (H-12-18-1901) and the other from the Nunatsiavut Government Research Advisory Committee (NGRAC-21431201), feedback was provided on initial study questions. RB coordinated feedback on interview questions from various team members and revised drafts of the interview guide. When completed, the questions were pilot tested with two initial interviews. After the pilot test, RB added one question that asked what lens they used to view the issue of food security. This question was added as the participant was approached based on their role. Through the initial pilot test, RB realized that the policy role was not the only lens impacting their views. For example, it could be a professional lens, Inuit identity, or others, in addition to their official role. The final set of questions were used for the remaining interviews. The interview guide is located in Appendix A.

\section{Participant selection and recruitment}

Two methods, purposeful and snowball sampling, were used to identify potential interview participants. We chose these methods to ensure the sample could provide "the type of knowledge necessary to understand structures and processes of local context" (28). We identified 17 potential participants through purposeful sampling from a previous study (29) that identified policies that pertained to food security in Nunatsiavut. Five additional potential participants were identified through snowball sampling. No further participants were sought when data saturation was reached. Participants were recruited by sending emails requesting an interview.

\section{Data collection}

RB sent each participant an invitation to participate that included an introduction to the interviewer and overview of the research project, a consent form and interview questions in advance of the interview. Written consent was obtained from each participant prior to the interview. RB conducted interviews from July 2020 until December 2020 at a home office. Interviews were conducted via Zoom or by phone as it was not possible to travel within Canada because of COVID-19 travel restrictions. On average, interviews lasted one hour and 30 minutes. All interviews were audio recorded and transcribed verbatim. Each participant reviewed their transcript for accuracy and had another opportunity for input. All transcripts and written documents were anonymized before data analysis.

\section{Data analysis}

This study used a traditional thematic analysis that identified, analyzed, organized, described, and reported themes found within this data set (30). Data analysis was completed by one person who also transcribed the interviews. Transcripts were entered into the NVivo 12 qualitative analysis software (31). Data were organized through a first cycle coding that included attribute coding, which summarized participant information, and structural coding that organized the data by parent nodes based on question responses. The second cycle included pattern coding, which involved creating a list, or inventory, of nodes based on common participant responses. A codebook was created, and these codes informed the themes from the data (32). Study results are reported according to the recommendations in the Consolidated Criteria for Reporting Qualitative Research (COREQ) (33). Table 1 (see Appendix A) contains a completed checklist of the consolidated criteria. The study results were sent to participants via email 
for review. Any comments provided were incorporated into the study. Some participants did not have comments but indicated their approval of the study results via email.

Table 1: Consolidated criteria for reporting qualitative studies (COREQ): $32-$ item checklist 


$\begin{array}{ll}\text { Topic and item Guide } & \text { Listed in text and page number } \\ \text { No. } & \text { questions/description }\end{array}$

Domain 1: Research team and reflexivity

\section{Personal Characteristics}

$\begin{array}{lll}\begin{array}{ll}\text { 1.Interviewer } \\ \text { facilitator }\end{array} & \begin{array}{l}\text { Which authors } \\ \text { conducted the } \\ \text { interview or focus } \\ \text { group? }\end{array}\end{array}$

2. Credentials What are the credentials?

\section{Occupation What was their occupation at the time of this study?} study. researcher's

The researcher's credentials are as follows: RB RDt.CDE M.Ad.Ed. GT, BScN, M.Ad. Ed., CF B.Sc., M.Sc., Ph.D. IDG PhD, FCAHS, FNYAM, FRSC, LD DPt, PhD. In addition to these credential the researcher's backgrounds are listed on p.5 of

The researchers occupations are as follows:

RB was a Ph.D. Candidate with the University of Ottawa, GT, is a Labrador Inuit Land Claims Beneficiary, CF is a full professor in the Department of Indigenous Studies and Sciences Program, Chanie Wenjack School for Indigenous Studies, Trent University, IDG is a Senior Scientist with the Centre for Practice-Changing Research, Ottawa Hospital Research Institute and a full professor with the School of Epidemiology and Public Health, Faculty of Medicine, University of Ottawa and LD is a full professor with the Faculty of Medicine School of Epidemiology and Public Health, University of Ottawa. They are listed on p.5 of study.

4. Gender Is the researcher male
or female?

$\begin{array}{ll}\text { 5. Experience } & \text { What experience or } \\ \text { and training } & \text { training does the } \\ \text { researcher have? }\end{array}$

The $\mathrm{Pl}$ is female. Of the remaining committee members, two members are female and two are male.

The PI has completed qualitative studies during her master's degree and has taken several courses in qualitative research and evaluation at the master's and $\mathrm{PhD}$ level. The other research committee members have extensive experience in research and many publications.

Relationship with participants

$\begin{array}{lll}\begin{array}{l}\text { 6. Relationship } \\ \text { established }\end{array} & \begin{array}{l}\text { Was a relationship } \\ \text { established prior to } \\ \text { the study } \\ \text { commencement? }\end{array} & \begin{array}{l}\text { Yes, as the PI and two other research team members have been involved with } \\ \text { other research studies involving the same population. Moreover, one research } \\ \text { team member is a beneficiary of the Labrador Inuit. Noted on p.5 of study. }\end{array}\end{array}$

7. Participant $\quad$ What did participants
knowledge of $\quad$ know about the knowledge of interviewer researcher? e.g., personal goals, reasons for doing the research.
8. Interviewer What characteristics characteristics were reported about the interviewer/facilitator?
The reasons for completing the research were provided with an overview of the study as per the University of Ottawa Ethics Materials. This information was provided to each participant prior to the interview. The materials were provided to each participant and are noted on $\mathrm{p} 5$.

The characteristics of the PI included her role in the study. This was noted in the introductory materials for the research project. These materials were provided to each participant and is noted on p.5.

Domain 2: Study design

Theoretical framework

$\begin{array}{ll}9 . & \text { What methodological None. } \\ \text { Methodological } & \text { orientation was stated } \\ \text { orientation and } & \text { to underpin the study? } \\ \text { theory } & \begin{array}{l}\text { e.g., grounded theory, } \\ \text { discourse }\end{array}\end{array}$

Participant selection

$\begin{array}{ll}\text { 10. Sampling How were participants Purposive and snowball sampling. Noted on p.6. of study. } & \text { selected? e.g., }\end{array}$ purposive, 
convenience,

consecutive, snowball

11. Method of approach

How were participants approached? e.g., face-to-face, telephone, mail, email

12. Sample size

How many participants were in the study?

\section{Non-} participation

How many people refused to participate or dropped out? Reasons?
Participants were approached via email. This was the only way possible as many people were working from home and could not be reached at work; there were also travel restrictions due to COVID-19. Noted on p.5 of study.

18. Noted on p.6 of study.

Five. No reasons were provided. Noted on p.6 of study.

\section{Setting}

14. Setting of data collection

Where was the data collected? e.g., home, clinic, workplace

15. Presence of Was anyone else nonparticipants present besides the participants and researchers?

\section{Description What are the most} of sample important characteristics of the sample? e.g., demographic data, date
At a home office. Due to the COVID-19 restrictions in place there was not an opportunity to work from anywhere else but home. The COVID-19 restrictions were noted on p. 5 of study.

No. Noted on p.5 of study.

Their role in a policy that pertained to food security in Nunatsiavut and/or their knowledge of food security in Nunatsiavut, self-identified gender, position, policy role. See table 2.

Data collection

17. Interview guide

18. Repeat interviews

19. Audio/visual recording

20. Field notes
Were questions, prompts or guides provided by the authors? Was it pilot tested?
The questions were provided in advance of the interviews. The questions were pilot tested with one person before the interviews started and the first two interviews served as a pilot for the remainder of the interviews. One question was added as a result of this pilot process. Research questions are located in available upon request. Noted on p.6 of study
Were repeat interviews carried out? If yes, how many?

Did the researcher use audio or visual recording to collect the data?

No. Noted on p.6 of study.

Yes. Audio equipment was used. Noted on p.6 of study.

Were field notes made during and/or after the interview or focus group?
Yes, memos were recorded immediately after each interview and notes were taken throughout the analysis process. Noted on p. 6 of study.

On average each interview was 1 hour and 30 minutes. Noted on p.6 of study.

\section{of the interviews or focus groups? \\ 21. Duration What was the duration}

$\begin{array}{ll}\text { 22. Data } & \text { Was data saturation } \\ \text { saturation } & \text { Yescussed? }\end{array}$

$\begin{array}{lll}\begin{array}{l}\text { 23. Returned } \\ \text { transcripts }\end{array} & \begin{array}{l}\text { Were transcripts } \\ \text { returned to } \\ \text { participants for } \\ \text { comment and/or } \\ \text { correction? }\end{array} & \begin{array}{l}\text { Yes, each verbatim transcript was returned to participants for verification. The } \\ \text { transcripts were reviewed by participants and returned to the researcher. Noted on }\end{array} \\ & \text { p.6 of study. }\end{array}$

Domain 3: Analysis and findings 


\begin{tabular}{|c|c|c|}
\hline $\begin{array}{l}\text { 24. Number of } \\
\text { data coders }\end{array}$ & $\begin{array}{l}\text { How many data } \\
\text { coders coded the } \\
\text { data? }\end{array}$ & One. Noted on p.6 of study. \\
\hline $\begin{array}{l}25 \text {. Description } \\
\text { of coding tree }\end{array}$ & $\begin{array}{l}\text { Did authors provide a } \\
\text { description of the } \\
\text { coding tree? }\end{array}$ & $\begin{array}{l}\text { A modified version was described in the results section, as there were two } \\
\text { separate analyses due to distinct questions asked about the COVID-19 } \\
\text { experience. Noted on p.6 of study }\end{array}$ \\
\hline $\begin{array}{l}26 \text {. Derivation } \\
\text { of themes }\end{array}$ & $\begin{array}{l}\text { Were themes } \\
\text { identified in advance } \\
\text { or derived from the } \\
\text { data? }\end{array}$ & They were derived from the data. Noted on p. 6 of study \\
\hline 27. Software & $\begin{array}{l}\text { What software, if } \\
\text { applicable, was used } \\
\text { to manage data? }\end{array}$ & NViVo version 12. Noted on p.6 of study. \\
\hline $\begin{array}{l}\text { 28. Participant } \\
\text { checking }\end{array}$ & $\begin{array}{l}\text { Did participants } \\
\text { provide feedback on } \\
\text { the findings? }\end{array}$ & Yes. Noted on p.6 of study. \\
\hline \multicolumn{3}{|l|}{ Reporting } \\
\hline $\begin{array}{l}\text { 29. Quotations } \\
\text { presented }\end{array}$ & $\begin{array}{l}\text { Were participant } \\
\text { quotations presented } \\
\text { to illustrate the } \\
\text { themes/findings? Was } \\
\text { each quotation } \\
\text { number identified? } \\
\text { e.g., participant } \\
\text { number }\end{array}$ & Yes. See pages 7-14. \\
\hline $\begin{array}{l}\text { 30. Consistent } \\
\text { data and } \\
\text { findings }\end{array}$ & $\begin{array}{l}\text { Was there consistency } \\
\text { between the data } \\
\text { presented and the } \\
\text { findings? }\end{array}$ & Yes. See pages 7-14. \\
\hline $\begin{array}{l}\text { 31. Clarity of } \\
\text { major themes }\end{array}$ & $\begin{array}{l}\text { Were major themes } \\
\text { clearly presented in } \\
\text { the findings? }\end{array}$ & Yes. Each of themes are presented individually. See pages 7-14. \\
\hline $\begin{array}{l}\text { 32. Clarity of } \\
\text { minor themes }\end{array}$ & $\begin{array}{l}\text { Is there a description } \\
\text { of diverse cases or } \\
\text { minor themes? }\end{array}$ & Yes, when applicable. See pages 7-14. \\
\hline
\end{tabular}

\section{Results}

In total, 15 semi-structured interviews were completed (13 out of 17 from purposeful sample and two out of five from snowball sample). No repeat interviews were conducted. Three participants (two from purposeful sample and one from snowball sample) provided written responses. Five people did not respond to a request for an interview. RB prepared notes prior to the interview, completed the interviews, and completed memos immediately after each interview. RB is from Labrador and previously worked as a health professional in Labrador, including Nunatsiavut as a health professional. Therefore, the topic and area were familiar to RB. The results are presented in three parts. Part 1 describes the role of participants; Part 2 provides an overview of policy actors' recommendations for improving policies that pertain to food security and existing gaps; Part 3 describes the policy actors' observations about food security in Nunatsiavut while implementing emergency food security measures during the first wave of COVID-19 in Nunatsiavut.

\section{Part 1: Overview Of Participants}

The majority of participants (78\%) self-identified as female and $22 \%$ self-identified as male. Of the total participants, ten (56\%) were employed by the Nunatsiavut Government, four (22\%) were employed by the provincial government (Newfoundland and Labrador), two (11\%) were employed by the federal government (Government of Canada), one participant (6\%) was employed by a 
non-governmental organization and one participant $(6 \%)$ by private industry. Thirteen participants $(72 \%)$ stated they worked with policies that directly pertain to food security, two participants $(11 \%)$ stated they worked indirectly with policies pertaining to food security and three (17\%) reported not working within the area of food security policy. Seven participants (39\%) stated they developed policy, six participants (33\%) stated they both developed and implemented policy and implementation, and five participants $(28 \%)$ considered policy implementation as their main role. Participants were not asked about Inuit identity. Only two participants identified their lens, which was a health professional lens. Table 2 (see Appendix A) contains an overview of participant characteristics.

Table 2

Overview of participant characteristics and roles

\begin{tabular}{|c|c|c|c|c|c|c|c|c|}
\hline $\begin{array}{l}\text { Participant } \\
\text { Number }\end{array}$ & $\begin{array}{l}\text { Self- } \\
\text { identified } \\
\text { gender }\end{array}$ & $\begin{array}{l}\text { Nunatsiavut } \\
\text { Government }\end{array}$ & $\begin{array}{l}\text { Provincial } \\
\text { Government }\end{array}$ & $\begin{array}{l}\text { Federal } \\
\text { Government }\end{array}$ & $\begin{array}{l}\text { Private } \\
\text { Industry/ } \\
\text { NGO }\end{array}$ & $\begin{array}{l}\text { Policy } \\
\text { Development }\end{array}$ & $\begin{array}{l}\text { Policy } \\
\text { Implementation }\end{array}$ & Both \\
\hline $\begin{array}{l}\text { Participant } \\
1\end{array}$ & Female & $x$ & & & & & & $x$ \\
\hline $\begin{array}{l}\text { Participant } \\
2\end{array}$ & Female & $x$ & & & & & & $x$ \\
\hline $\begin{array}{l}\text { Participant } \\
3\end{array}$ & Female & & & & $x$ & & $x$ & \\
\hline $\begin{array}{l}\text { Participant } \\
4\end{array}$ & Female & & $x$ & & & $x$ & & \\
\hline $\begin{array}{l}\text { Participant } \\
5\end{array}$ & Female & & $x$ & & & $x$ & & \\
\hline $\begin{array}{l}\text { Participant } \\
6\end{array}$ & Female & & $x$ & & & $x$ & & \\
\hline $\begin{array}{l}\text { Participant } \\
7\end{array}$ & Female & $x$ & & & & & & $x$ \\
\hline $\begin{array}{l}\text { Participant } \\
8\end{array}$ & Female & $x$ & & & & & $x$ & \\
\hline $\begin{array}{l}\text { Participant } \\
9\end{array}$ & Male & & & $x$ & & $x$ & & \\
\hline $\begin{array}{l}\text { Participant } \\
10\end{array}$ & Female & $x$ & & & & & $x$ & \\
\hline $\begin{array}{l}\text { Participant } \\
11\end{array}$ & Male & $x$ & & & & & & $x$ \\
\hline $\begin{array}{l}\text { Participant } \\
12\end{array}$ & Male & & & $x$ & & & & \\
\hline $\begin{array}{l}\text { Participant } \\
13\end{array}$ & Female & $x$ & & & & $x$ & & \\
\hline $\begin{array}{l}\text { Participant } \\
14\end{array}$ & Female & $x$ & & & & & & $x$ \\
\hline $\begin{array}{l}\text { Participant } \\
15\end{array}$ & Male & $x$ & & & & & $x$ & \\
\hline $\begin{array}{l}\text { Participant } \\
16\end{array}$ & Female & & & & $x$ & & $x$ & \\
\hline $\begin{array}{l}\text { Participant } \\
17\end{array}$ & Female & $x$ & & & & $x$ & & \\
\hline $\begin{array}{l}\text { Participant } \\
18\end{array}$ & Female & & $x$ & & & $x$ & & \\
\hline
\end{tabular}


Part 2: Policy actors' recommendations pertaining to policies for food security in Nunatsiavut

Seven themes were identified from the key informant interviews. They ranged from awareness of the food security issue within Nunatsiavut to issues with current policies and recommendations for improving current policies that pertain to food security.

\section{Theme 1: Improving food security is a priority for the Nunatsiavut Government}

"One of the things I know is that food security is becoming a really top topic." (participant 8)

Participants from Nunatsiavut stated that food security is a priority within the region. There is increased awareness by staff working within Nunatsiavut and the general public, as Nunatsiavut Government staff receive suggestions from the general public on actions to improve food security. Participants identified a variety of factors that contributed to the increased awareness. These included food security projects in the region, communication of recent research study results showing the prevalence of food security on a regional and community level, placing food security on the Department of Social Health and Development Plan, and community level food security working groups, including one that has existed for ten years. However, with increased awareness people within Nunatsiavut also reached out with ideas for food security programming (participant one).

An increased awareness came with an expectation for the Nunatsiavut Government to act quickly. This brought forward discussions on both types of programs and policy interventions required and the Nunatsiavut Government's capacity to respond to this issue. Most Nunatsiavut Government participants stated that their programs had a component or activity that addressed food security. In addition, the Nunatsiavut Government increased their capacity to support all aspects of food security-including programming, policy and advocacy through having dedicated staff. The Nunatsiavut Government has a permanently funded core team focused on food security that includes regional policy and coordinator roles and community level worker positions. Participants reported that while a success, challenges remain such as staffing positions and a high turnover that impacts implementing community-based and regional activities.

Food security as a priority is increasing for the provincial and federal government. Participants from both the provincial and federal government stated they were aware that food security is an issue for Nunatsiavut and there is a need to continue to work on this issue with the Nunatsiavut Government.

\section{Theme 2: Labrador Inuit context is always a key consideration in policy making}

"The Indigenous perspective is an important part of any work we do." (participant 18)

All participants stated that Labrador Inuit interests were an important consideration for policy development and implementation. For the Nunatsiavut Government, a focus on Labrador Inuit was paramount as they represent the needs of Labrador Inuit. However, the degree to which the Labrador Inuit context is addressed was seen to depend on two factors: the policy focus and degree of policy flexibility during implementation. Regarding focus, at times "the Labrador Inuit context was the reason for implementing a policy" (participant three) and the particular policy. For other policies, especially those developed by the Government of Canada or Province of Newfoundland and Labrador, Labrador Inuit were a part of a larger overarching policy that considered Indigenous contexts, but not specifically Labrador Inuit. The Labrador Inuit context was tailored during implementation but at times this depended on policy flexibility. At times, it was up to the "Indigenous group to identify how to best spend the money" (participant six). In other instances, the Nunatsiavut Government had to implement the policy according to predetermined activities.

\section{Theme 3: Factors impacting food security in Nunatsiavut}

"You can't share what you don't have." (participant 11)

Participants noted the breadth of factors that impacted food security, including mental health, substance use disorders and climate change. However, participants cited four consistent factors including lack of available country food and market food, lack of access to market food, lack of income to purchase food and/or lack of food skills. 
Eight participants, seven from the Nunatsiavut Government and one from a non-government organization, stated lack of country food availability, namely the loss of caribou, was a factor that severely impacted food security within Nunatsiavut due to the lack of a nutritious food and "the cultural transmission has been lost" (participant three). The loss is due to the George River caribou herd hunting ban that stopped all caribou hunting within Nunatsiavut. To compensate for this loss, several policies exist to support hunting and transporting moose meat from Newfoundland to northern Labrador to support community freezers within Nunatsiavut. However, this program only supplements country food. As participant 11 explained, "Yeah. So, it's not intended to replace access to George River caribou because people would have had enough caribou in their freezer, but it is a way to supplement country food. It is not a way to replace the loss of the George River caribou. It cannot, it is just not enough."

All participants stated that market food availability is impacted by transportation and storage. In winter, airplanes transport food and in summer food is transported by airplane and boat. Air transportation infrastructure issues such as short runways impact the size of planes that can land. These small planes (Twin Otters) limit the amount of food that can physically be brought into a community at one time. Moreover, there are no storage facilities at airports or boat docks. The lack of transportation infrastructure and storage impacts food quality, and accordingly, availability and access. As participant 16 stated, "Fresh fruit is like, how fresh is it once you get it? For a couple of weeks just recently, all of our fresh berries and our lettuce and stuff like that, it just went right into the garbage bin. It was already developing mold. So, the quality of what we're getting up here is horrible, but we're still paying the cost of the freight to get it here. And then it goes into the trash can. And then the people are not having their fresh fruits and vegetables for that week because you just had to throw it all in the garbage."

All participants stated that food prices are a factor impacting access to market food. However, participants from the Nunatsiavut Government provided insight into the factors influencing transportation costs and electricity costs. Participants stated that even with a subsidy, electricity costs are higher in northern Labrador. This impacts food costs when almost $75 \%$ of a building is used for storage and requires electricity. Also, freezer repair costs for grocery stores and community freezers are a unique consideration as the repair person must fly into the community. This means repair costs start when the person travels and can include an hourly wage for two or three days, flight costs and accommodation. There is also no guarantee the issue can be fixed at that time, possibly requiring another visit to complete the task.

All participants stated that a lack of income to buy food was a significant factor impacting access to market food. Participants stated those with income issues, including people who rely on income support payments, have short-term employment and/or minimum wage jobs that were not adequate to cover the cost of living, and specifically, the cost of food in northern Labrador.

Finally, participants suggested the lack of food skills was another factor impacting food security. The skills noted ranged from budgeting and cooking market foods to the preparation of country foods. Participants from Nunatsiavut, the provincial government and the federal government involved with policies that focused on nutrition education and/or country foods, surmised the lack of food skills-both market foods and country foods-were due to residential school experiences that prevented learning these skills from immediate and extended family. Participants also stated these experiences negatively impacted some people's relationship with food.

\section{Theme four: Improving policies for food security within Nunatsiavut}

"There's always room for improvement." (participant 11)

Given the breadth of factors impacting food security in Nunatsiavut, all participants identified policy improvements and/or policy gaps. Generally, participants outside of Nunatsiavut did not comment on how policies could be improved, as they felt it was not within their purview. However, they could identify policy gaps based on their knowledge of the issue. Participants provided suggestions for improving policy in three areas: policy transparency, air transportation infrastructure and income support. Three policy gaps noted were regulation of both food and freight prices and sharing country food across the north. Wildlife monitoring was considered both an area of improvement and a policy gap.

Participants cited policy transparency as an area of improvement. This is important as it supports policy improvement through understanding what is not working with a particular policy. Nutrition North Canada was often cited as an example of a policy that lacked transparency. For example, participant one stated, "I think the more transparency that we can infuse into how all these

Page $11 / 22$ 
systems work, the better we'll be able to understand them and understand what can be changed, what can't, what needs to be done differently. But a lot of these policies seem to be black boxes to the average person."

A second area of improvement identified by participants was air transportation infrastructure. Suggestions for improvement consisted of improved airport runway length, which would allow for bigger planes to transport food. Another suggestion was to have storage facilities at airports and docks to ensure food was adequately stored when transportation issues such as delayed flights or unexpected landings occurred. There was only one suggestion to improve shipping. This suggestion included increasing the number of boats that travel to the north coast of Labrador in the summer due to the short shipping season.

Income support was the third area of policy improvement. This was suggested as participants deemed current income support rates insufficient to provide enough money for food and other costs of living. However, suggestions for improvement differed. Some proposed that the policy should be increased to the cost of living in northern Labrador, whereas others recommended removing this policy altogether and replacing it with a Guaranteed Basic Income funded at sufficient levels.

Regulation of food prices and freight prices were identified as policy gaps. Several participants expressed their disbelief that alcohol prices are regulated but not food or transportation. Participant 10 stated: "Why can't they regulate milk? It has to cost a lot to get beer and because shipping is based on weight. What I don't understand is, it shouldn't be permitted that the price of a two liter of milk should not exceed X amount of dollars. But yet it does." Participants felt stabilizing freight prices through regulation would promote lower and consistent food costs. Another policy gap noted for country food was sharing country foods across areas of the north. There are policies in place to encourage country food consumption within Nunatsiavut, but they can only encourage consumption of foods that exist. Sharing country food was suggested as there is a caribou ban in place in Labrador but not in the other Inuit land claim areas. However, within Nunatsiavut other country foods are available such as seal and char.

Participants considered monitoring of fish and wildlife both an area of improvement and a policy gap. The Nunatsiavut Government develops and monitors fish and wildlife limits for personal use or for economic development. However, there is not a lot of scientific data to support limits set by the Nunatsiavut Government, and accordingly participants viewed this as an area for improvement. The Federal Government of Canada monitors species but only those at risk. Participants considered the lack of monitoring for species other than those at risk a policy gap.

\section{Theme five: Policy effectiveness reduced because of lack of policy coherence}

"You won't get buy-in from people to try new foods and you know, if the food costs are just too out of reach for them and their families in the communities." (participant nine)

Related to, but distinct from policy improvement and gaps, is the lack of policy coherence during implementation among some policies that pertain to food security. For example, the lack of effectiveness of Nutrition North Canada negatively impacts the effectiveness of the Nutrition North Canada Education Initiatives and the nutrition education component of community-based programs. As participant nine stated, "The challenge that we often hear is that we can do all of the nutrition education that we want, within communities. It is important, but if the costs of these foods are still too high and are not affordable, the nutrition education part of the program suffers when the subsidy part of the program is not working to bring food costs down. They go hand in hand."

Another example of policy incoherence in implementation is Nutrition North Canada and income support. As participant seven stated, "Nutrition North subsidizes fresh produce, that's like one of their priority areas. And the thing is, if you are impoverished, and you are getting $\$ 12,000$ a year, you know, broken out into cheques or whatever, from the Government of Newfoundland, if you only have a budget of like $\$ 30.00$ on groceries and a bag of peppers costs $\$ 10.00$ you know, if you only have like $\$ 9.00$ to spend on vegetables, it doesn't matter that the peppers only cost $\$ 10.00$ instead of $\$ 20.00 . "$

In one example, one policy inhibited another policy activity. As participant 14 stated, "Last year, we had plans to do an outing and then we received notification from Transport Canada that we were no longer allowed to use, like, local people in the community to take people in [a] speedboat, for example, to do different activities that we had planned." In this example the Transport Canada policy that did not allow local people in the community to bring others for hunting or fishing. This action impacted delivery of

Page $12 / 22$ 
hunting and fishing activities that are focused on country food skills. These activities are part of a policy that is focused on food security and climate change.

\section{Theme six: Everyone shares the responsibility for food security within Nunatsiavut}

"Nobody's ultimately responsible, everybody has responsibility." (participant nine)

Most of the respondents stated that food security is a shared responsibility that "goes right back to the supplier, to the transportation system, to different levels of government, to the retailers, so there's a lot of people that would be factors that play in food security for sure" (participant three). It also included community members as "community members also have a responsibility to take care of each other; that was and is the Inuit way" (participant two). Three participants disagreed on responsibility: one participant stated it was a provincial responsibility and two participants stated it was an individual responsibility.

However, participants stated responsibility was not shared equally across jurisdictions. This depended on jurisdictional issues as each level of government operates within their own area of influence, roles and mandates. Three participants stated that the provincial government shared more of a responsibility due to their role in social policies and transportation. For example, participant one stated, "There's elements that are related to food security that the Nunatsiavut Government has no control of, like an example would be minimum wage. That's not in our jurisdiction, but it's directly impacting us." Participant 13 stated, "So even though you have the airstrip in Nain...it's sitting there. That's a provincial jurisdiction for transport even though it's sitting in your land claims area?"

Also, when partners are not fulfilling their responsibility, it impacts progress towards policy goals. For example, not all Indigenous groups within Labrador are implementing the hunting ban on George River caribou herd and it is not enforced by the Province of Newfoundland and Labrador. As participant 11 stated, "The province has a mandate to ensure compliance with their hunting ban and they seem to be very lax on enforcing the ban order. There's no will, or very little will to ensure compliance when a group is saying that they're not going to follow the guidelines."

Defined structures and strength of relationships impacted how responsibilities were negotiated and shared. As participant 11 stated, "We do have a lot of working relationships with the federal and provincial governments because we need to do that, in order to be able to do our jobs." When these relationships exist and effective mechanisms are established, it leads to collaborative decision making, supports mutual priorities and leverages opportunities such as funding.

\section{Theme seven: Inequitable treatment of Labrador}

"You know, being in Labrador, we're kind of the last people to be served." (participant 15)

Throughout the interviews, participants from Nunatsiavut voiced a sense of resignation as things have not seemed to change over time since they were developed, despite the known difficulties with issues such as transportation. Participant 17 stated: "I mean, I just can't believe how in this day and age how unequal it is. It is almost like they're just resigned to the fact that the north coast communities have to pay this much to travel, to buy their foods, and it's not right."

One participant explained that one of the reasons why these issues continue to persist is related to the lack of questioning and accepting the status quo. Participant seven explained that, “Speaking from a cultural trait, most people won't question. While this can be considered a beautiful cultural trait, it can have a negative impact when people are not questioning why things are the way they are as it can lead to a lack of accountability by governments and private industry."

Part 3: What did the Nunatsiavut Government learn about food security in Nunatsiavut from implementing the COVID-19 emergency responses?

In April 2020, the Nunatsiavut Government instated a Food Supplement Program specific to "supporting individuals and families impacted by COVID-19 and those most vulnerable to the virus" (27). For market food, the program included vouchers for food. Priority for programming was given to "seniors aged 60 years and older who were on fixed incomes, people living with disabilities, 
single parents, low-income families receiving income support, living on fixed-pension incomes or employment insurance, and individuals and families who have had their employment hours cut or have been laid off because of the pandemic." (27).

These emergency measures were developed and implemented very quickly; in essence it was the first of its kind for food security within Nunatsiavut. While these measures pertain to food security, they are temporary. Given these factors, a separate thematic analysis was conducted on the responses for the COVID-19 Food Supplement Program implemented in Nunatsiavut. As this experience augmented discussions on current policy approaches to improving food security in Nunatsiavut, the results are included in this study.

Most of the responses on the Nunatsiavut policy implementation were provided by Nunatsiavut Government participants. Those outside of Nunatsiavut did not comment on the particular interventions, but rather the issue of food security and COVID-19 more broadly. Five themes emerged from experience of providing the emergency Food Supplement program implemented during the first wave of COVID-19 in 2020.

Theme one: Halting community-based programs due to COVID-19 restrictions showed gaps in emergency food system responses.

"COVID-19 has highlighted the challenges that exist in the emergency food response system." (participant 18)

Participants described how food security within Nunatsiavut is usually supported through community-based programming via health services, community freezers and school-based interventions that all have a food component. When these activities were restricted due to pandemic measures, very few measures were available to support food security in Nunatsiavut, creating an urgency for emergency food supplements. Additionally, COVID-19 impacted food sharing practices among community members and households. Participant 7 stated, "So those that needed to have a lot shared with them, that couldn't happen. So, we were really isolated." While the Nunatsiavut Government could continue to support hunting and community freezers, there were no mechanisms to provide market food through community programs. This was a gap, and the subsequent basis for the Food Supplement program.

Theme two: The impact of COVID -19 travel restrictions increased awareness of interconnectedness of the market food system.

"I think it [COVID -19] has highlighted how fragile the food system is." (participant 11)

Participants noted that food could only be provided if it was available. As a result of COVID-19 restrictions, the reliance on the broader food supply, storage and transportation services were highlighted as issues impacting food availability. As transportation routes were disrupted, it was difficult to obtain required goods. This was compounded by the lack of inventory in the spring of the year. Inventory is ordered in the fall of the year, and stores tend to have low inventory by spring. New food orders are placed when the marine system starts in the late spring/early summer. Through the COVID-19 experience participants realized the vulnerability of the broader food system.

Theme three: The impacts of the COVID-19 lockdown showed the number of people living on the edge of poverty in Nunatsiavut.

"A lot of people had extreme difficulty, especially seniors and those that were close to the poverty level." (participant seven)

During the initial COVID-19 lockdown, some people within Nunatsiavut temporarily lost employment and required assistance. These people required extra support during COVID-19 as during usual times they are living on the edge of poverty. As participant 17 stated, "We were aware of it before with the survey, but we saw a lot more during COVID-19."

Theme four: The need for COVID-19 measures demonstrated the inadequacy of usual policy approaches to food security.

"One thing I know that we started running into, was that like, the stores aren't used to people having money." (participant 10)

The Food Supplement program provided enough supports that people could buy adequate amounts of food to eat. This impacted stores and as participant 16 stated, "The store started running out of stock for like a lot of stuff because suddenly people had access to money that they wouldn't normally have access to, and also specifically money that was like, not just cash that they could spend on anything, you know, but like, specifically on food." Participants who were responsible for implementing the

Page $14 / 22$ 
program stated that the emergency measures highlighted the inadequacy of current policy approaches to food security that focus on income i.e., income support and do not provide enough supports to buy adequate amounts of food. The COVID-19 experience also highlighted the need to work on longer term action on poverty.

Theme five: The COVID-19 emergency responses prompted discussions on the future of food security within Nunatsiavut

“We're currently developing a survey to send to people throughout the government about to reflect on what they learned. Like through the service delivery that we've been doing." (participant 13)

The Nunatsiavut Government implemented the COVID-19 Food Supplement. Providing emergency relief was a new role for the food security team, and more generally for the Nunatsiavut Government. This experience offered those working on food security within Nunatsiavut an opportunity to include food security as part of emergency responses, but also carries a risk that this could be considered a main part of food security efforts moving forward, pending funding. This experience has prompted discussions among policy actors on what is the scope of the role for food security efforts within Nunatsiavut and what could they learn from this experience to apply to approaches for improving food security in Nunatsiavut in the future? Participants from the provincial and federal governments also stated the COVID-19 experience has raised awareness of food security and prompted the same type of forward thinking about approaches for food security in the future.

\section{Discussion}

For Labrador Inuit in Nunatsiavut, and Indigenous Peoples in Canada broadly, food security is a complex issue impacted by many factors. The participants in this study highlighted key factors that impact food security for Labrador Inuit that can contribute to a better understanding of the issue. Moreover, as noted in the introduction, food security is considered a distinct determinant of Inuit health and is further impacted by health inequities. The World Health Organization Commission on the Social Determinants of Health provides principles and actions to improve health equity (3). Two of the World Health Organization principles are consistent with the participants' suggestions for improving food security. The first principle is improving the conditions of daily life that focus on creating social protection policies supportive of all and create conditions for a flourishing older life. The second principle is tackling the distribution of money, power and resources that address inequities in the way society is organized. This requires strengthened governance, from the community level to global institutions, and for people across society to agree on public interests and reinvest in collective action (3). These principles are consistent with the specific suggestions that pertain to the Nunatsiavut context and form the basis of improving policy responses for food security in Nunatsiavut, Labrador, Canada.

\section{Ensure policies address cultural aspects of food security for Labrador Inuit}

Study participants identified a range of factors that impact food security in Nunatsiavut. These included income support rates, climate change and loss of wildlife, transportation and food costs. These factors are consistent with previous studies completed in Nunatsiavut $(34,35)$ and within the rest of Canada $(5)$. Two factors focused on Inuit culture and how their loss contributes to a lack of food security. These factors were a lack of food skills and the loss of country foods due to the George River caribou herd hunting ban.

For Inuit and other Indigenous Peoples in Canada food skills pertain to market food and country food. Within the general Canadian population, a 2016 study showed that food skills and cooking ability for adults in food insecure households did not differ from others and were not associated with the odds of household food insecurity when sociodemographic characteristics were taken into account (36). However, participants in this study noted that market food skills are an area of improvement and should be further incorporated into future policy and programming efforts. Traditional food education, specifically teaching traditional food skills in the family, was perceived as a facilitator of food security among Inuit in Nunavut (37).

Participants in this study noted a loss of traditional food skills and mainly attributed the loss of food skills to the impact of residential schools that disrupted family teaching of traditional food skills. This finding is consistent with other publications on residential schools and Inuit health $(38,39)$. Work has begun to repair the relationship with food. As participant 17 stated, "We are talking about positive memories of food for the first time." And participant 14 stated that improving traditional food skills is also a

Page 15/22 
focus. One success has been focusing on traditional food skills in current policies that pertain to food security, as these activities receive positive evaluations by participants.

From both a cultural and sustainability perspective, the loss of the George River caribou herd is one of the greatest perceived impacts on food security within Nunatsiavut. As participant 17 stated, "Everybody's suffering from not being able to, to go out and hunt caribou." Other studies noted the same impact on Labrador Inuit in which participants explained that food security was ultimately dependent on the land's ability to support healthy populations of animals and vegetation (34). Caribou is both a source of nutrients for Inuit and a connection to the land $(34,40,41)$. The caribou ban has led to an emotional response from Labrador Inuit that includes grief, sadness and frustration (40). As noted previously, working towards removing the hunting ban will require efforts from others besides Labrador Inuit and reinforce the need for collaborative decision-making mechanisms.

In addition to providing insight into the factors that contribute to a lack of food security for Labrador Inuit, these factors highlight a limitation of the existing food security dimensions of access, availability, utilization and stability (42). For First Nations and Inuit in Canada, cultural food security has been defined as the ability to reliably access important traditional foods through traditional harvesting methods, including hunting, fishing and gathering, to ensure the survival of their cultures $(43,44)$. Alonso et al. (45) have built on this initial definition to state that food security exists when there is the availability, access, utilization (i.e., food preparation, sharing and consumption; foodways) and stability of cultural foods. Others have suggested that culture should be a separate dimension of food security $(44,46)$. Including culture food security as a part of food security strategies and as a separate dimension is consistent with the Inuit Right to Food (24). These suggestions can be part of future discussions on making food security dimensions relevant for Inuit in Canada, and Indigenous Peoples more broadly.

\section{Develop a food security in all approach to policy development and implementation}

Throughout multiple themes of this study participants identified the need to improve policies from two perspectives, the effectiveness of the individual policy and the impact of one policy on another, which is referred to in the literature as policy coherence. Policy coherence is defined as "the systematic promotion of mutually reinforcing policies across government departments to create synergies towards achieving agreed objectives and to avoid or minimize negative spillovers in other policy areas" (47). Both effective policies and policy coherence are required to improve food security for Labrador Inuit.

Social protection across the life course is a critical aspect of improving health equity. The World Health Organization recommends that "social protection systems should be at a level that suffices for healthy living" (3). One source of social protection in Canada is income support which is the "program of last resort for working aged adults" (48). However, studies on income support and food security within Canada show that income support recipients are the most food insecure, as "two thirds of income support recipients report some sort of food insecurity" $(11,48)$. This is due to the amount of income support provided.

Participants in this study stated the amount of income support provided to recipients within Nunatsiavut did not provide enough money to buy adequate amounts of food and needs to be improved. Labrador Inuit who qualify receive income support from the Province of Newfoundland and Labrador. A recent analysis of income support rates in Newfoundland and Labrador showed that by all income cut-off measures, a family of four on income support in St. John's, the capital of the Province of Newfoundland and Labrador, would be living in "deep poverty" (49). The costs of living on the northern Labrador coast are higher. For example, focusing only on food costs, the Government of Newfoundland and Labrador's calculations for the cost of a weekly food basket are $56 \%$ higher for northern Labrador than St. John's (50). Yet, according to the Newfoundland and Labrador Legislation on income support, there is only an $8.5 \%$ increase for a family of four receiving income support living on the coast of Labrador (51). The need for a Food Supplement Program by income support recipients during COVID-19 augmented existing evidence of the insufficient amounts and demonstrated that when community-based supports are not available, structural determinants such as social policies become even more important to support people experiencing food insecurity.

Research on improving income support shows that food insecurity among social assistance recipients in two Canadian provinces, Newfoundland and Labrador (12) and British Columbia (15), improved when income support benefit levels increased. There is also an increased call for a Guaranteed Basic Income as a way forward after COVID-19 for all provinces in Canada (52), a feasibility study is underway in Nunavut (53) and a Guaranteed National Income is a recommendation in the recently released National Inuit

Page $16 / 22$ 
Action Plan on Missing and Murdered Inuit Women, Girls, and 2SLGBTQQIA+ people, specifically action item 4.2 that states: To reduce poverty among Inuit, the federal government must develop a national basic income model in partnership with Inuit that, when implemented, will support Inuit families living around or below a jurisdiction's poverty line (54). From these study results, it was difficult to determine if improving the existing policy is preferred over a new approach. This will have to be determined in further conversations with Labrador Inuit and will depend on the political and economic factors post COVID-19. Regardless of the mechanism, improving social policies can improve food security and health equity.

The World Health Organization states policy coherence is crucial for health equity. Policy coherence and food security have been studied for specific aspects of food security in South Africa (55), agricultural policies in the Organisation for Economic Cooperation and Development (48) and across the European Union (56). Policy incoherence is when policies aim for different goals and are made in isolation from each other. This raises the risk of differing policy objectives, outcomes and impacts (57). Policy incoherence undermines achieving common goals, which in this study is improving food security. Within this study, participants identified policy implementation experiences that exemplified policy incoherence.

As an individual policy, several issues including lack of transparency and effectiveness have been noted about the Nutrition North Canada program in previous studies $(11,15)$ and were reiterated by participants in this study. These issues impacted the effectiveness of Nutrition North Canada program and contributed to policy incoherence during policy implementation as it did not support other policy outcomes, namely effective nutrition education and access to food. However, the Nutrition North Canada program is also impacted by other policies, namely increased freight costs and landing fees for airplanes, which are set by the Province of Newfoundland and Labrador (58).

Improving policy coherence is an important consideration for the person who is experiencing food insecurity as they may be the recipient of several policy interventions. To improve policy coherence, policy development, implementation and evaluations need to take into account other policies that pertain to food security. This begs the consideration for food security in all approach that includes intersectoral action due to the number of policies outside of health and measuring policy coherence as a part of policy evaluation. Beyond these factors, due to the number of governments that develop and implement policies, established roles must be defined and mechanisms must be in place at all levels of government to advance a food security in all approach.

\section{Develop mechanisms to ensure the Nunatsiavut Government is included in policy development by other jurisdictions}

Political empowerment -inclusion and voice is one of the actions listed within principle two for improving health equity, namely tackle the inequitable distribution of money power and resources (3). To achieve this goal there are two specific suggestions for what must be done. The first is "Strengthen political and legal systems to protect human right, assure legal identity and support the needs and claims of marginalized groups, particularly, Indigenous Peoples" and "Ensure the fair representation and participation of individuals and communities in health decision-making as an integral feature of the right to health." (3). The Nunatsiavut Government is a self-government; however, this government has a unique role compared to federal and provincial governments. The Nunatsiavut Government has to both govern Labrador Inuit and advocate for policy change to other governments (federal and provincial) when required. Recent media reports citing requests from the Nunatsiavut Government to address transportation issues in the region (59), or during discussions on Nutrition North Canada (60) are examples of Nunatsiavut Government advocacy to address gaps in policies that pertain to food security. The advocacy role can require aligning with other non-governmental organizations or Indigenous organizations.

The variety of roles is one of the reasons Wilson and Per Sele (18) state that Inuit regional governance extends along both the vertical continuum (e.g., local, regional, national and international levels) and horizontal continuum (Inuit organizations such as land claims organizations, and national and transnational organizations). Each of these levels have government or nongovernment policy actors that play a role in advocating for, implementing and/or developing policies that pertain to food security in Nunatsiavut.

At times, the Nunatsiavut Government may be part of processes that represent both horizontal and vertical continuums. One example is the direct engagement between Inuit leaders from the Inuit Tapiriit Kanatami and the Inuit Land Claim areas and the Government of Canada through the Inuit-Crown Partnership Committee (25). For Nunatsiavut this mechanism represents a

Page $17 / 22$ 
horizontal continuum with Inuit Tapiriit Kanatami and a vertical continuum with the Government of Canada. This same mechanism does not exist within the Government of Newfoundland and Labrador. Rather, a separate government department is largely responsible for focusing on social and economic issues within Labrador and engages the Nunatsiavut Government. However, this department does not lead all of the policies that pertain to food security, but rather is more of a consultation and coordinating mechanism within the provincial government. This type of engagement appears to align with shared rule as noted by Wilson and Per Sele (18), rather than being consistent with self-determination as outlined in the United Nations Declaration on the Rights of Indigenous Peoples (17).

To improve health equity and to improve governance of policies that pertain to food security, mechanisms for engaging with the Nunatsiavut Government or with Nunatsiavut Government program representatives need to be established and maintained with the Province of Newfoundland and Labrador. These mechanisms provide the opportunity to ensure the Nunatsiavut Government is involved in the development and implementation of policies that affect them.

\section{Learning from a pandemic: Key insights from implementing the COVID-19 Food Supplement Program}

Within Nunatsiavut, the press release on the latest budget stated: "Many Labrador Inuit continue to experience high levels of food insecurity. The impacts have been much more visible since the start of the pandemic." (61). The COVID-19 experience showed that usual policy approaches to food security were not sufficient in times of a pandemic and there was a gap in emergency programming that had to be filled quickly. Stability is a dimension of food security that states people must be able to access food at all times and in times of shock or crisis (42). Therefore, next steps and future discussions need to focus on how approaches to food security will emphasize the stability dimension of food security. Also, the Nunatsiavut Government showed leadership in response to the COVD-19 pandemic. However, this came at a cost to other programs as people redirected work to focus on the safety of communities and ensuring required supports were implemented. The focus on emergency food supply during COVID-19 posed the question of the future role of food security within Nunatsiavut.

\section{Limitations}

The limitations in this study were due to the participant selection and inability to travel to Nunatsiavut and the number of people completing data analysis. Firstly, the participant selection process of purposeful and snowball sampling could have missed potential participants. Including more participants from outside of Nunatsiavut and from other governments and nongovernmental organizations may have revealed additional issues. However, given most study participants had direct experience with policy implementation within Nunatsiavut the views obtained in this study reflected the reality of the circumstances of policy implementation in Nunatsiavut. Furthermore, we were reassured that our findings were credible given that data saturation was reached with the participants included in the study. Another limitation was the inability to travel to the community to complete inperson interviews. This prevented an in-person connection between the Principal Investigator and participants, and a fulsome observation of body language by the Principal Investigator. The remaining limitation was that only one person, RB, completed the interviews and data analysis. To overcome this limitation, and improve credibility, member checking was completed with participants and the team members provided feedback on the themes and data analysis.

\section{Conclusion}

The results from this study provide an overview of a few distinct factors that contribute to the low state of food security for Labrador Inuit, provide suggestions for improving policy and demonstrate how a policy is developed is as important as the policy itself for Indigenous Peoples. The emphasis on food security during the COVID-19 pandemic provides an opportunity to consider approaches for improving efforts to address food security. This study demonstrated that improving policy responses for food security are consistent with suggested actions for improving health equity. A post COVID-19 response may not mean doing more of the same, but rather taking actions to ensure a fair and more just approach to improving food security for Labrador Inuit. It is our intention and hope that this article contributes to these improved actions among policy actors in various roles-from advocacy to implementation-who focus on policies that pertain to food security. And ultimately, work towards improving food security for Labrador Inuit in Nunatsiavut. 


\section{Declarations}

\section{Ethics approval and consent to participate}

Both the University of Ottawa (H-12-18-1901) and the Nunatsiavut Government Research Advisory Committee (NGRAC-21431201) provided ethics approval for this project. Informed written consent was sought and provided by each participant of this study.

\section{Consent for publication}

Not applicable

\section{Availability of data and materials}

The datasets used and/or analysed during the current study are available from the corresponding author on reasonable request.

\section{Competing Interests}

The authors declare they have no competing interests.

\section{Funding}

None. IDG is a recipient of a CIHR Foundation Grant FDN \# 143237.

\section{Authors' contributions}

All authors contributed to the questionnaire design and conception of the study. RB completed the key informant interviews, completed the thematic analysis and wrote the original draft and revisions of the study. LD provided feedback on the analysis. LD, GT, IDG and CF critically appraised drafts and provided significant input into this study. All authors read and approved the final manuscript.

\section{Acknowledgements}

The authors would like to acknowledge Labrador Inuit Lands and the Nunatsiavut Government Advisory Group who provided invaluable input to this study.

\section{References}

1. Inuit Tapiriit Kanatami. Inuit Food Insecurity Canada I The Nuluaq Project [Internet]. 2021 [cited 2021 March 24];[about 1 screen]. Available from: https://www.itk.ca/nuluaq-mapping-project/inuit-food-insecurity-canada-background/

2. Inuit Tapiriit Kanatami. Social Determinants of Inuit Health in Canada [Internet]. Ottawa, Canada; Inuit Tapiriit Kanatami, September 2014 [cited 2021 May 14]. Available from: https://www.itk.ca/wpcontent/uploads/2016/07/ITK_Social_Determinants_Report.pdf

3. World Health Organization Commission on the Social Determinants of Health. Closing the gap in a generation: Health equity through action on the social determinants of health - Final report of the commission on social determinants of health - Final report [Internet]. Geneva; The World Health Organization, 2008 [cited 2021 May 14]. 256 p. Available from: WHO_IER_CSDH_08.1_eng.pdf

4. Gibson M. Food Security-A Commentary: What Is It and Why Is It So Complicated? Foods [Internet]. 2012 Dec [cited 2021 June 10];1(1):18-27. Available from: doi: 10.3390/foods1010018

5. Tarasuk V, Mitchell A. Household food insecurity in Canada, 2017-18. Toronto: Research to identify policy options to reduce food insecurity (PROOF) [Internet]. 2020 [cited 2021 Mar 6]. Available from: https://proof.utoronto.ca/

6. St-Germain A, Galloway T, Tarasuk V. Food insecurity in Nunavut following the introduction of Nutrition North Canada. CMAJ [Internet]. 2019 May [cited 2021 June 10];191(20):E552-E558.Available from: https://doi.org/10.1503/cmaj.181617 
7. Fafard St-Germain A, Tarasuk V. Homeownership status and risk of food insecurity: examining the role of housing debt, housing expenditure and housing asset using a cross-sectional population-based survey of Canadian households. Int $J$ Equity Health. 2020;19(1):5. doi:10.1186/s12939-019-1114-z

8. Brown E, Tarasuk V. Money speaks: Reductions in severe food insecurity follow the Canada Child Benefit. Prev Med[Internet]. 2019 June [cited 2021 June 10];129:105876. Available from: https://doi.org/10.1016/j.ypmed.2019.105876

9. Chin-Yee M, Chin-Yee L. Nutrition North Canada: Failure and Facade within the Northern Strategy. Univ Toronto Med J[Internet]. 2015[cited 2021 June 10];92(3).Available from: https://utmj.org/index.php/UTMJ/article/view/215/321

10. Galloway T. Is the Nutrition North Canada retail subsidy program meeting the goal of making nutritious and perishable food more accessible and affordable in the North?. Can J Public Health. 2014;105(5):e395-e397. doi:10.17269/cjph.105.4624

11. Tarasuk V, Li N, Dachner N, Mitchell A. Household Food Insecurity in Ontario during a Period of Poverty Reduction, 2005-2014. Can Public Policy. 2019;45(1):93-104. doi: 10.3138/cpp.2018-054

12. Li N, Dachner N, Tarasuk V. The impact of changes in social policies on household food insecurity in British Columbia, 20052012. Prev Med. 2016;93:151-158. doi:10.1016/j.ypmed.2016.10.002

13. Ionescu-Ittu R, Glymour M, Kaufman J. A difference-in-differences approach to estimate the effect of income-supplementation on food insecurity. Prev Med. 2015;70:108-116. doi:10.1016/j.ypmed.2014.11.017

14. Galloway T. Canada's northern food subsidy Nutrition North Canada: a comprehensive program evaluation. Int J Circumpolar Health[Internet]. 2017 [cited 2021 June 10];76(1):1279451. Available from: https://doi.org/10.1080/22423982.2017.1279451

15. Loopstra R, Dachner, N, Tarasuk, V. An exploration of the unprecedented decline in the prevelance of household food insecurity in Newfoundland and Labrador 2007-2012. Can Public Policy. 2015;41(3):191-206. doi: 10.3138/cpp.2014-080

16. Bastian A, Coveney J. The responsibilisation of food security: What is the problem represented to be?. Health Sociol Rev. 2013;22(2):162-173. doi:10.5172/hesr.2013.22.2.162

17. UN General Assembly, United Nations Declaration on the Rights of Indigenous Peoples: resolution / adopted by the General Assembly, A/RES/61/295 [Internet]. 2 October 2007 [cited 2021 Mar 29]. Available from:

https://www.refworld.org/docid/471355a82.html

18. Wilson, Gary N., and Per Selle. Indigenous Self-Determination in Northern Canada and Norway. IRPP Study 69 [Internet]. Montreal: Institute for Research on Public Policy 2019 [cited 2021 Mar 21]. Available from: https://doi.org/10.26070/jc5j-5162

19. Shannon, M.A. FAO Forestry Paper 142. Chapter 5 Mechanisms for Coorsindation. [Internet] [cited 2021 May 20]. Available from: http://www.fao.org/3/y4653e/y4653e08.htm

20. McIntyre L, Jessiman-Perreault G, Mah C, Godley J. A social network analysis of Canadian food insecurity policy actors. Can J of Diet Prac Res. 2018;79(2):60-66. doi: 10.3148/cjdpr-2017-034.

21. Inuit Tapiriit Kanatami. An Inuit Specific Approach for the Canadian Food Policy [Internet]. Ottawa; Inuit Tapiriit Kanatami; 2017 [cited 2021 Mar 29]. 40 p. Available from: https://www.itk.ca/wp-content/uploads/2019/01/ITK_Food-Policy-Report.pdf

22. Inuit Food Security Working Group. Nutrition North Program Engagement, Written Submission[Internet].Ottawa: Inuit Tapiriit Kanatami, 2016 [cited 2021 May 14]. 7p. Available from: https://www.itk.ca/wp-content/uploads/2017/10/Appendix-I-InuitFood-Security-Working-Group-NNC-Engagement-Written-Submission.pdf

23. Inuit Tapiriit Kanatami. An Inuit-Specific Approach for the Canadian Food Policy [Internet]. Ottawa; Inuit Tapiriit Kanatami, 2017 [cited 2021 May 14]. 36 p. Available from: https://www.itk.ca/inuit-specific-approach-for-canadian-food-policy/

24. Inuit Tapiriit Kanatami and Inuit Circumpolar Council. n.d. Inuit and the Right to Food. Ottawa, Canada

25. Crown and Indigenous Northern Affairs Canada[Internet]. Ottawa: The Government of Canada; 2018. Inuit permanent bilateral mechanism - Inuit-Crown Partnership Committee. 2018 April 3 [cited 2021 Mar 27];[about 1 screen]. Available from: https://www.rcaanc-cirnac.gc.ca/eng/1499711968320/1529105436687

26. Labrador Inuit land claims agreement Act S.C.2005, c27 1050 [Internet]. Ottawa: Government of Canada, 2019 Jun 20 [cited 2021 Mar 20]. Available from: https://laws-lois.justice.gc.ca/eng/acts/L-4.3/index.html

27. Nunatsiavut Government. COVID-19 Food Supplement Program in place for Labrador Inuit in Consituency of Canada 2020 [press release] (April 24, 2020) [cited 2021 Mar 27]. Available from: https://www.nunatsiavut.com/article/covid-19-foodsupplement-program-in-place-for-labrador-inuit-in-constituency-of-canada/. 
28. Popay J, Rogers A, Williams G. Rationale and Standards for the Systematic Review of Qualitative Literature in Health Services Research. Qual Health Res.1998;8(3):341-351. doi: 10.1177/104973239800800305.

29. Bowers R, Turner G, Graham I.D, Furgal C, Dubois L. Piecing together the Labrador Inuit food security policy puzzle in Nunatsiavut, Labrador (Canada): a scoping review. Int J Circumpolar Health [Internet]. 2020 Dec [cited 2021 June 10];79(1):1799676. Available from: https://doi.org/10.1080/22423982.2020.1799676

30. Nowell, L.S., Norris, J.M., White, D.E., Moules,N.J. Thematic Analaysis:Striving to Meet the Trustworthiness Criteria. Int J Qual Methods[Internet]. 2017 October [ cited 2021 June 10] 16:1-13. Available from: https://doi.org/10.1177/1609406917733847

31. NVivo Qualitative Data Analysis Software [Software] [Internet]. 1999. Available from: https://qsrinternational.com/nvivo/nvivo-products/.

32. Saldaña J. The coding manual for qualitative researchers. 3rd ed. Sage; 2016.

33. Tong A, Sainsbury P, Craig J. Consolidated criteria for reporting qualitative research (COREQ): a 32-item checklist for interviews and focus groups. Int J Qual Health Care [Internet]. 2007 September [cited 2021 June 10];19(6):349-357. Available from: https://doi.org/10.1093/intqhc/mzm042

34. Harper S, Edge V, Ford J, Willox A, Wood M, McEwen S. Climate-sensitive health priorities in Nunatsiavut, Canada. BMC Public Health [Internet]. 2015 July[cited 2021 June10];15:605. Available from: https://doi.org/10.1186/s12889-015-1874-3

35. Cunsolo Willox A, Harper S, Ford J, Landman K, Houle K, Edge V. "From this place and of this place:" Climate change, sense of place, and health in Nunatsiavut, Canada. Soc Sci Med. 2012;75(3):538-547. doi:10.1016/j.socscimed.2012.03.043

36. Husken A, Orr S, Tarasuk V. Adults food skills and use of gardens are not associated with household food insecurity in Canada.Can J Pub Health. 2017;107(6), e526-e532. Available from: doi: 10.17269/cjph.107.5692

37. Chan H, Fediuk K, Hamilton S, Rostas L, Caughey A, Kuhnlein H et al. Food security in Nunavut, Canada: barriers and recommendations. Int J Circumpolar Health. 2006;65(5):416-431.doi: https://doi.org/10.3402/ijch.v65i5.18132

38. Procter A. A long Journey:Residential Schools in Newfoundland and Labrador. St.John's Newfoundland, ISER publications. 2020.

39. Truth and Reconciliation Commission of Canada. Canada's Residential Schools: The Inuit and Northern Experience. The Final Report of the Truth and Reconciliation Commission of Canada V2. McGill Queen's University Press [Internet]. 2015 [cited 2021 Mar 21]. 289 p Available from: http://www.trc.ca/assets/pdf/Volume_2_Inuit_and_Northern_English_Web.pdf

40. Cunsolo A, Borish D, Harper S, Snook J, Shiwak I, Wood M et al. "You can never replace the caribou": Inuit Experiences of Ecological Grief from Caribou Declines. American Imago. 2020;77(1):31-59. doi:10.1353/aim.2020.0002.

41. Natcher D, Shirley S, Rodon T, Southcott C. Constraints to wildlife harvesting among aboriginal communities in Alaska and Canada. Food Secur. 2016;8(6):1153-1167. https://doi.org/10.1007/s12571-016-0619-1

42. Food and Agricultural Organization. An introduction to the basic concepts of food security. Food security for action practical guides. Rome, Italy. EC-FAO food security programme [Internet]. 2008 [cited 2021 Mar 19]. Available from: http:// 930 www.fao.org/3/al936e/al936e00.pdf

43. Chan L RO, Sharp D, Schwartz H, Ing A, Tikihonov C. First Nations Food, Nutrition and Environment Study: Results from British Columbia (2008-2009). Prince George, BC: University of British Columbia; 2011.

44. Power E. Food security of First Nations and Inuit in Canada: background paper. Ottawa, ON: First Nations and Inuit Health Branch, Health Canada; 2007.

45. Alonso E. B., Cockx L., \& Swinnen J. Culture and food security. Glob Food Secur.2018; 17, 113-127. https://doi.org/10.1016/j.gfs.2018.02.002

46. Tarraf, D, Sanou D, Giroux I. Immigration and Food Insecurity: The Canadian Experince -A Literature Review. In. Muensternman I, editor. People's Movements in the 21st Century - Risks, Challenges and Benefits [book on the internet]. Intech Open Books; 2017 [cited 2021 Mar 27]. p 37-53. Available from: https://www.intechopen.com/books/people-smovements-in-the-21st-century-risks-challenges-and-benefits/immigration-and-food-insecurity-the-canadian-experience-aliterature-review

47. Organisation for Economic Co-operation and Development. Better Policies for Sustainable Development 2016: A New Framework for Policy Coherence, OECD Publishing, Paris[Internet]. 2016 [cited 2021 Mar 29]. Available from:

Page $21 / 22$ 
https://doi.org/10.1787/9789264256996-en.

48. Tarasuk V, Fafard St-Germain A, Mitchell A. Geographic and socio-demographic predictors of household food insecurity in Canada, 2011-12. BMC Public Health.[Internet] 2019 January [cited 2021 June 20];19(12).Available from:

https://doi.org/10.1186/s12889-018-6344-2

49. Stadelmann-Elder M. Welfare in Canada - Newfoundland and Labrador[Internet]. - Maytree; 2020 [cited 2021 March 29 ]. Available from: https://maytree.com/welfare-in-canada/newfoundland-and-labrador/

50. Department of Statisics. Newfoundland and Labrador Nutritious Food Basket: monitoring the cost of healthy eating [Internet]. Government of Newfoundland and Labrador; 2018 [cited 2021 Mar 29]. Available from: https://www.stats.gov.nl.ca/Publications/pdf/NNFB_2018_09_13_v04.pdf

51. Income and Employment Support Act 2019 SNL2002 Chapter I-0.1 (Newfoundland and Labrador) [Internet]. [cited $2021 \mathrm{Mar}$ 29] Available from: https://www.assembly.nl.ca/legislation/sr/statutes/i00-1.htm

52. Canada's first Basic Income Bill:C-273 [Internet]. UBI Works; 2021 June 21[cited 2021 June 26]. Available from: https://www.ubiworks.ca/basicincomebill

53. McKay, J. Nunavut to look at guaranted basic income program [Internet]. Canadian Broadcasting Corporation, 2020 Sept 28 [updated 2020 Sept 28; cited 2021 June 10]. Available from: https://www.cbc.ca/news/canada/north/nunavut-incomeassistance- 1.5739646

54. Inuit Tapiriit Kanatami and Pauktuutit Inuit Women of Canada. National Inuit Action Plan on Missing and Murdered Inuit Women, Girls and 2SLGBTQQIA+ People [Internet].Ottawa; Inuit Tapirrit Kanatami, 2021[cited 2021 June 26]. 58 p. Available from: https://www.itk.ca/wp-content/uploads/2021/06/20210602-mmiwg-inuit-action-plan-full-EN.pdf

55. Thow A, Greenberg S, Hara M, Friel S, duToit A, Sanders D. Improving policy coherence for food security and nutrition in South Africa: a qualitative policy analysis. Food Secur.[Internet] 2018 June [cited 22 June 2018];10(4):1105-1130.Available from: https://doi.org/10.1007/s12571-018-0813-4

56. Brooks J. Policy coherence and food security: The effects of OECD countries' agricultural policies. Food Policy. 2014; 44:8894. https://doi.org/10.1016/j.foodpol.2013.10.006

57. Parsons, K. Brief 3. Integrated Food Policy. What is it and how can it help transform food systems?[Internet]. London; Centre for Food Policy, 2019 [cited 2021 June 10]. 8 p. Available from: https://www.city.ac.uk/_data/assets/pdf_file/0008/491174/7643_Brief-

3_Integrated_food_policy_What_is_it_and_how_can_it_help_connect_food_systems_WEB_SP.pdf

58. Department of Transportation and Infrastructure. Provincial Airports [Internet]. St.John's; Government of Newfoundland and Labrador,.n.d.[cited 2021 Mar 15]. Available from: https://www.gov.nl.ca/ti/airportservices/

59. Nain's airstrip is failing, and pressure is mounting for the province to help [Internet]. Canadian Broadcasting Corporation, 2020 Nov 6 [updated 2020 Nov 6; cited 2021 Mar 29]. Available from: https://www.cbc.ca/news/canada/newfoundlandlabrador/nain-airstrip-pressure-to-fix-provincial-government-1.5790602

60. Nunatsiavut says federal gov't not committed to fixing misaligned northern food subsidy program [Internet]. Canadian Broadcasting Corporation. Oct, 28, 2018 [cited 2021 Mar 28]. Available from: https://www.cbc.ca/news/canada/newfoundland-labrador/nutrition-north-nunatsiavut-1.4874906

61. Nunatsiavut Government. Budget focuses on governance, infrastructure and enhancing programs and services [press release] (March 19, 2020) [cited 2021 March 19]. Available from: https://www.nunatsiavut.com/wp-content/uploads/2020/03/Budgetfocuses-on-governance-infrastructure-and-enhancing-programs-and-services.pdf

\section{Supplementary Files}

This is a list of supplementary files associated with this preprint. Click to download.

- AppendixABMCHE.docx

Page 22/ 22 